\title{
"COVID-19 and investor sentiment influence on the US and European countries sector returns"
}

Pedro Manuel Nogueira Reis (D https://orcid.org/0000-0003-1301-6645

AUTHORS

R https://publons.com/researcher/1887144/pedro-m-nogueira-reis/

Carlos Pinho (D https://orcid.org/0000-0002-7422-4555

R https://publons.com/researcher/C-2033-2015

Pedro Manuel Nogueira Reis and Carlos Pinho (2020). COVID-19 and investor ARTICLE INFO sentiment influence on the US and European countries sector returns. Investment Management and Financial Innovations, 17(3), 373-386. doi:10.21511/imfi.17(3).2020.28

DOI http://dx.doi.org/10.21511/imfi.17(3).2020.28

RELEASED ON Thursday, 08 October 2020

RECEIVED ON

Thursday, 09 July 2020

ACCEPTED ON

Tuesday, 29 September 2020

\section{(c) EY}

LICENSE

This work is licensed under a Creative Commons Attribution 4.0 International License

JOURNAL

"Investment Management and Financial Innovations"

ISSN PRINT $1810-4967$

ISSN ONLINE $1812-9358$

PUBLISHER

LLC "Consulting Publishing Company "Business Perspectives"

FOUNDER LLC "Consulting Publishing Company "Business Perspectives"

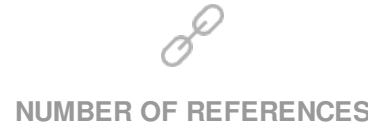

33

\section{NUMBER OF FIGURES}

2
NUMBER OF TABLES

7

(C) The author(s) 2021. This publication is an open access article. 


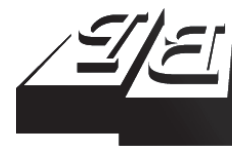

BUSINESS PERSPECTIVES

(O)

LLC "CPC "Business Perspectives" Hryhorii Skovoroda lane, 10 Sumy, 40022, Ukraine www.businessperspectives.org
Received on: $9^{\text {th }}$ of July, 2020 Accepted on: $29^{\text {th }}$ of September, 2020 Published on: $8^{\text {th }}$ of October, 2020

(๑) Pedro Manuel Nogueira Reis, Carlos Pinho, 2020

Pedro Manuel Nogueira Reis, Ph.D. in Finance, Assistant Professor, School of Management, Polytechnic Institute of Viseu; Center for Research in Digital Services (CISeD), Campus Politécnico de Repeses, Portugal. (Corresponding author)

Carlos Pinho, Ph.D. in Applied Economics, Associate Professor, Department of Economics, Management and Industrial Engineering and Tourism, University of Aveiro, Portugal.

\section{COVID-19 AND INVESTOR SENTIMENT INFLUENCE ON THE US AND EUROPEAN COUNTRIES SECTOR RETURNS}

\begin{abstract}
Although some studies recently address the association between COVID-19 sentiment and returns, volatility, or stock trading volume, no one conducts an analysis to measure the impact of investor rationality or irrationality on the influence on countries and sectors' returns.

This work creates a text media sentiment and combines its influence with the outbreak cases on the stock market sector returns of the US, Europe, and their main countries most affected by the pandemic.

This allows us to perceive the ranking impact of rationality or irrationality on country and sector stock returns. This work applies a random-effects robust panel estimation, with an M-estimator. This paper concludes that US returns are more sensitive to sentiment, and thus more prone to irrational factors than confirmed cases compared to Europe and that country factors influence the returns differently. In Italy and Spain as the most punished countries in Europe apart from the UK, present sector indexes return more reactive to verified cases, or rationality, namely, tourism, real estate, and the automobile (this last one in Italy).

The importance of this work resides in providing a new in-depth analysis of irrational behavioral metrics among countries, which allows for comparison. Moreover, it al lows observing which sectors' and which countries' asset returns are most sensitive to rational or irrational expressions of events, allowing for arbitraging, financial planning for investors, decision-makers, and academia on an in and out of pandemic context.
\end{abstract}

\section{Keywords coronavirus, pandemic, panic, fear, contagion, spillover, index}

JEL Classification G15, G40

\section{INTRODUCTION}

COVID-19 pandemic affected everyone worldwide. A death rate in Europe of 9.4\%, 6\% for the Americas and 3\% for Asia, and a high contagion rate have created the economic and social chaos infecting 5 million people worldwide and 330 thousand deaths (May 19th, 2020). Although the death rate seems to be decreasing, the number of cases is going up. The US (with 1,529,000) and Europe $(1,740,000)$ present a higher number of cases and within Europe, the United Kingdom with 248,818 , Spain with 232,037 , Italy with 226,699 , Germany with 176,007 , and France with 143,427 , lead the ranking. The death rate seems to be decreasing in Europe (from February till May; 2.17\%, 7.36\%, 15.66\%, and $14.60 \%$, respectively) and the US (from March till May; $1.93 \%$. 6.60\%, 6.33\%, respectively) (European Centre for Disease Prevention and Control, 2020).

Academia has widely proven that financial asset prices movement is also explained by sentiment, mainly in periods of irrational, unjustified panics or exaggerated optimism. Investor sentiment is related to 
emotions, pessimism, or optimism that can influence the investment decisions and, thus, asset prices, as documented by Benhabib, Liu, and Wang (2016), Jitmaneeroj (2017). The sentiment is documented as the deviation bias between asset price sustained by fundamentals and its current price (Zhou, 2018; Giglio \& Kelly, 2017), which can be considered mispricing.

If the share price deviates from its theoretical price, then sentiment plays a determinant role to justify the difference. Stock prices can thus become irrational. Accordingly, the Eugene Fama Efficient Market Hypothesis, characterized by a market full of well-informed investors, investments properly priced, and reflecting all available information, is not sustained. That is why market efficiency for asset pricing has been put in question by behavioral finance. Investors are biased and irrational, and these behavioral features play a determining role in asset prices. When incorporated into the models' supply, investor behavior is an explanation for stock returns and volatility. Sharma and Kumar (2019) defend that researchers should present robust behavioral asset pricing models backed by enough empirical evidence worldwide, incorporating investor psychological biases in new robust behavioral asset pricing models. Also, Aggarwall (2019) sustains that financial theories' sentiment construct needs to be revisited according to the sentiments defined in psychology.

Sentiments can be defined as phantasy relationships built unconsciously in mind (Tuckett \& Taffer, 2008). This can lead to emotional speculations about future price movements. Perceiving sentiments and human cognition will lead to an understanding of market asset pricing. The impact of decision-making over rational investments built upon company fundamentals or sustained on decisions made upon available information of real events, and irrationality - measured as an expectation based on feelings and not real premises - should be studied and compared in terms of sector and countries' performance.

Accordingly, this paper addresses a new approach by comparing the asset price reaction to verified events (immediate emotions) against those events' anticipation through investor sentiment (lagged and expected emotions) to observe market and sector returns biases regarding psychological behavior. This work intertwines a real psychological event as the fear and panic caused by the COVID-19 pandemic, with a text investor sentiment index that captures the anxiety embedded in different countries' and sectors' stock markets. The importance of the theme lies in the fact that by knowing which sectors and which countries are most reactive to rational or irrational expressions of events, institutional investors, companies providing financial information, political and academic professionals can anticipate market reactions and thus monitor procedures, information, and arbitraging. In academic terms, in addition to meeting the suggested academic gaps in the works of Sharma and Kumar (2019) and Aggarwall (2019), it serves to create the path for the measurement and monitoring of the causes that influence these behaviors to provide the market with an antidote to minimize the asymmetric impacts of erratic behavior and peak levels of sector and country asset exchanges. Furthermore, this work allows analyzing which country is more sensitive to irrational behaviors and compares them, which will contribute to the solution of the sentiment different bias among stock markets. Therefore, this work's research question is to find which country and sector returns response is more prone to rational or irrational behavior. This work is structured as follows: after this introduction section, the recent literature review is provided, then the methods, afterward, the results and their discussion, and finishing with the concluding remarks.

\section{LITERATURE REVIEW}

\subsection{The rationality and irrationality of sentiment}

Fama and French (2015) assume that 28\% remains unexplained and possibly attributed to investor feelings, sentiment, or irrationality on explaining stock returns besides company fundamentals. Managers can be optimistic or pessimistic beyond fundamentals driving to irrational market consequences (Greenwood \& Shleifer, 2014). The irrationality of analysts, which is reflected by their optimistic forecasts, may be 
attributed to the inconsistent reactions to news or scenario thinking (Sedor, 2002). Brown and Cliff (2004) and Baker and Wurgler (2006) define investor sentiment index as an irrational factor index. Chaoqun et al. (2018) defend that the ability of investor sentiment as a predictor of stock returns does not derive from a rational forecast of future cash flows, but, instead, irrational behavior.

Traditional finance theory defends that stock prices reflect the discounted value of expected cash flows and that arbitrageurs eradicate the impact of irrational behavior by investors, but behavioral finance suggests that waves of irrational sentiment - optimistic or pessimistic expectations - can persist and influence asset prices for significant periods of time and consequently cause crises (Zouaoui et al., 2011).

The rational part of the sentiment comes from the expectation of the behavior of future cash flows based upon the company fundamentals, or real news or events that may influence future firm financial behavior. The irrational part comes from over-optimism or pessimism, like panic or exaggerated fear that is subjective. Hirshleifer (2015) shows that investor sentiment is the fluctuating attitude to investment categories, and it may be associated with changes in assessments of expected returns or risk. This attitude might include waves of irrational enthusiasm or repugnance for certain investment characteristics and shifts in the emotional or cognitive opinion that the economic environment triggers. If sentiment brings mispricing, then sentiment measures should predict future abnormal returns.

Many authors compute investor sentiment measure using survey-based measures as the consumer sentiment index or economic sentiment indicators as proxies, or text data sustained upon media collection of words or based on data analysis.

Investor sentiment - the irrational part - is calculated as the error term of a regression between the sentiment proxy and macroeconomic variables or fundamentals to remove the "rational term". The random error term captures the in- vestor sentiment, or the irrational components, and the fitted (predicted values within the model) of that regression capture the rational components of sentiments (Baker \& Wurgler, 2006; Reis \& Pinho, 2020a, b; Sayim \& Rahman, 2015; Verma, Baklaci, \& Soydemir, 2008).

Verma et al. (2008) defend that irrational sentiments have a more rapid and pronounced effect on stock market returns than rational sentiments. They defend that the individual and institutional investor sentiments are driven by rational and irrational factors with different effects on stock market returns. They consider the role of economic fundamentals as determinants of stock market returns, which is the rational part of the authors' sentiment. This rational part of sentiment has a much greater effect on returns explanation than the sentiments-induced by noise or irrational. If excessive optimism drives prices above intrinsic values, periods of high sentiments should be followed by low returns as market prices revert to fundamental values. They also find that rational sentiments are incorporated in stock prices at a slower speed than the irrational sentiments. Verma et al. (2008) define as the rational part of the sentiment the company fundamentals that justify the returns and the irrational part of the error term of the regression between returns and fundamentals.

\subsection{The pandemic}

Zhang, $\mathrm{Hu}$, and Ji (2020) show that global financial market risks strongly increased during the COVID-19 pandemic. Country stock market reactions relate to the severity of the outbreak. Markets became volatile, unpredictable, and characterized by uncertainty due to economic losses, causing the downgrade market. Gunay (2020) studies the correlations across different stock markets before and after the pandemic and concludes that Chinese and Turkish stock markets weaken from 2005 to 2019, but display a $20 \%$ rise following the outbreak. Other market pairs (US, UK, Italy, Spain) show correlation coefficients at $10 \%$. Corbet et al. (2020) state that cryptocurrencies do not act as hedges or safe havens in times of serious financial and economic disruption, but, instead, as amplifiers of 
contagion. Gold does not present any relation with Chinese stock markets and does not appear to be a safe haven. Baker et al. (2020) defend the biggest stock market volatility caused by the COVID-19 when compared to other historic pandemics such as the bird flu (1997-1998), SARS (2003), swine flu (2009), Ebola and MERS (2014 to 2015), coronavirus (COVID-19, from December 2019 to date). Papadamou, Fassas, Kenourgios, and Dimitriou (2020) built a google trend index concerning coronavirus and studied their impact on the implied volatility of thirteen major stock markets, covering Europe, Asia, USA, and Australia regions founding that increased search queries for COVID-19 present a direct effect on implied volatility, and an indirect effect via stock returns emphasizing a risk-aversion channel operating around pandemic conditions. Onali (2020) suggest that changes in the number of cases and deaths in the US and other countries majorly affected by the COVID-19 crisis in the first three months of 2020 (China, Italy, Spain, the UK, Iran, and France) do not have an impact on the US stock market returns, but reveal evidence of a positive impact on the conditional heteroscedasticity of the Dow Jones and S\&P returns.

A. M. Al-Awadhi, Al-Saifi, A. Al-Awadhi, and Alhamadi (2020) found that growth in total cases and deaths caused by COVID-19 has a significant negative effect on stock returns across all companies in the Chinese stock market.

Most studies prove a reverse association among sentiment and future market returns as the works of Fisher and Statman (2000), Ding, Mazouz, and Wang (2018), Baker and Wurgler (2006). However, Cheema and Szulczyk (2020) find a strong positive association between investor sentiment and later market returns during the bubble period. Outside the bubble period, investor sentiment has a negligible impact on market returns. Also, Lee, Jiang, and Indro (2002) subscribe to an identical positive relation.

This work interlaces a real psychological event as the fear and panic caused by the COVID-19 pandemic, with a text investor sentiment index that captures the anxiety embedded in different countries and sectors stock markets.
Accordingly, this work's research question is to find which country and sector returns response is more prone to rational or irrational behavior.

\section{METHOD}

Although most studies address the relation amongst COVID-19 sentiment and returns, volatility, or stock trading volume, no one conducts an analysis towards measuring the effect of the rationality of investors on the influence on countries' and sectors' returns. The rational reaction can be measured through real events, where irrationality can be portrayed by sentiment behavior when expecting upcoming events (see Verma et al., 2008, about rational and irrational behavior). The authors' method is divided into three phases: 1) the building of the index sustained on Google Trends; 2) the orthogonalization trough ordinary least squares against macro variables; 3 ) the data analysis using panel data robust analysis with random effects. This work based the sentiment index on the method proposed by Gao, Ren, and Zhang (2018) that applied households' Google search behavior to construct sentiment indices for different markets. They show that their sentiment measure is a contrarian predictor of country-level market returns. Also, the work of Schatteman and Waymire (2017) contributes to the choice of words for our sentiment. This paper relies on the Merriam-Webster dictionary and finds negative words classified in the group of "econ". This work proceeds with the search of the words on the news from Reuters, CNBC, Bloomberg, and Wall Street Journal websites as from April 2004 till April 16 $6^{\text {th }}, 2020$.

Then the combined terms in Google Trends "market crash + depression + recession + "short selling" + panic + default + bankruptcy + losses" are searched to come up with the sentiment index in the subgroup "companies and industries" from 2015 till April 19 ${ }^{\text {th }}, 2020$. This form of words combination code allowed us to check simultaneously whichever of those words were searched specific words were translated into the country language using Google Translate. Accordingly, this work produces a sentiment index with a range value between 0 and 100, 
Table 1. Words search inserted on the news from 2004 till 2020, April $16^{\text {th }}$ (million)

\begin{tabular}{|c|c|c|c|c|}
\hline Words & WSJ & CNBC & Bloomberg & Reuters \\
\hline Short & 38 & 21 & 106 & 169 \\
\hline Loss & 40 & 11 & 59 & 81 \\
\hline Crash & 6 & 7 & 25 & 47 \\
\hline Default & 29 & 15 & 61 & 96 \\
\hline Depression & 21 & 5 & 24 & 35 \\
\hline Recession & 2 & 5 & 18 & 35 \\
\hline Bankruptcy & 2 & 1 & 13 & 17 \\
\hline Panic & 4 & 2 & 12 & 13 \\
\hline
\end{tabular}

meaning that a value of 100 is a very low sentiment (fear, panic, pessimism), implicating an increase in those search words, and 0 otherwise.

Considering that macroeconomic factors may influence this sentiment proxy and thus be biased, to capture real irrational and rational behavior related to the sentiment, this paper follows Baker and Wurgler's (2006) procedure to orthogonalize the index against three macroeconomic variables (Brent, sovereign 10-year yield, and Bitcoin) trough ordinary least squares. Brent and sovereign yield allow us to withdraw systematic risk and bitcoin the speculative risk. Afterward, the residuals are used as true sentiment measure:

$$
\begin{aligned}
& \text { Sent }_{t, i}=\beta \cdot \text { brent }_{t, i}+ \\
& +\beta \cdot \text { sovereignyield }_{t, i}+ \\
& +\beta \cdot \text { bitcoin }_{t, i}+\text { Sent }_{t, i}^{\perp},
\end{aligned}
$$

where $S e n t_{t, i}^{\perp}$ is the true sentiment corresponding to the error term of expression 1, Sent, raw sentiment, Brent price, the sovereign yield for the 10 -year term, and Bitcoin price; $t$ is the time and $i$ is the country.

Then with COVID-19 cases and the sector and global country index returns, this paper carried on a panel data regression analysis with robust (heteroscedasticity and serial correlation, robust standard errors) with random effects (verified after the performance of the Hausman test) for European countries (UK, France, Italy, Spain,
Germany) and individual robust standard errors OLS regressions for individual European countries and the US.

Robust regressions use not only an M-estimator (Huber followed by bisquare) but also include a first step that removes high-leverage outliers (based on Cook's D) (Maronna, 2006; Huber, 1973). The standard least-squares method tries to minimize the error, which is unstable if there are outliers present in the data. Outlying data give such a strong effect in the minimization that the parameters thus estimated are distorted. The M-estimator reduces outliers' effect by replacing the squared residuals by another function of the residuals, yielding more optimal estimators (Zhang, 1997). The sentiment measure and cases are standardized with zero mean and one standard deviation for more legible results:

$R_{i, t}=\beta R_{i, t-1}+\theta S_{i, t}+\vartheta C_{i, t}+\mu_{i, t}+\varepsilon_{i, t}$,

where $R$ is the index or the sector ETF return, $S$ is the standardized sentiment obtained in expression (1) and is $C$ the first lagged difference of coronavirus cases, with $\beta, \theta$ and $\vartheta$, the coefficients, $i$ is the country and $t$ is the time, with $\mu_{i, t}, \varepsilon_{i, t}$, mean the between entity and within entity error, respectively.

\section{RESULTS}

Table 2 presents the detailed variable descriptive statistics. 
Table 2. Summary statistics and variable definition

\begin{tabular}{|c|c|c|c|c|c|c|c|}
\hline Variable & Obs. & Mean & Std. Dev. & Min & Max & Database & Measure \\
\hline sent_negat & 1,211 & 27.01569 & 17.60223 & 0 & 100 & Google Trends & Sentiment \\
\hline cases & 839 & 2295.534 & 5719.023 & 0 & 48529 & $\begin{array}{l}\text { data.europa.eu/euodp/en/data/dataset/ } \\
\text { covid-19-coronavirus-data }\end{array}$ & No. of COVID-19 cases \\
\hline stoxx600 & 1,267 & -.0007723 & .0173687 & -.1147762 & .0840495 & investing.com & STOXX 600 index return \\
\hline eurotravel & 1,267 & -.0023793 & .0267959 & -.1328 & .1006 & investing.com & ETF STOXX Europe 600 travel and leisure return \\
\hline euroreal & 1,267 & -.0014754 & .0177446 & -.1146 & .0822 & investing.com & ETF STOXX Europe 600 real estate return \\
\hline euroauto & 1,267 & -.0023763 & .0259308 & -.1457 & .1565 & investing.com & ETF STOXX Europe 600 automobile return \\
\hline europetelec & 1,267 & -.0017093 & .0167538 & -.108 & .0898 & investing.com & ETF STOXX Europe 600 telecommunications return \\
\hline dowjones & 1,267 & -.0005639 & .0241721 & -.1227 & .1143 & investing.com & Dow Jones index return \\
\hline djoneshotel & 1,267 & -.0018109 & .0316052 & -.1462 & .1518 & investing.com & Dow Jones hotels index return \\
\hline djteleco & 1,267 & -.0006629 & .0184666 & -.0821 & .0821 & investing.com & Dow Jones telecommunications index return \\
\hline djauto & 1,267 & .0014743 & .0336356 & -.16 & .1576 & investing.com & Dow Jones automobiles index return \\
\hline djreal & 1,267 & -.001018 & .0273037 & -.1743 & .0853 & investing.com & Dow Jones real estate index return \\
\hline bitcoin & 1,204 & 7961.186 & 1224.003 & 4927 & 10339 & investing.com & Bitcoin price \\
\hline brent & 798 & 53.74123 & 16.27944 & 14.85 & 70.25 & investing.com & Brent price \\
\hline germ10y & 861 & -.3717317 & .1349276 & -.854 & -.182 & investing.com & 10y government yield (Germany) \\
\hline usa10y & 1,001 & 1.455252 & .4680767 & .502 & 1.945 & investing.com & 10y government yield (USA) \\
\hline
\end{tabular}

Note: Daily data from 2015 till April 2020, although COVID-19 cases just appear at the end of 2019. 
Table 3. Random effects panel regression results for the US and Europe

\begin{tabular}{|c|c|c|c|c|c|c|c|c|c|c|c|}
\hline \multicolumn{6}{|c|}{ USA } & \multicolumn{6}{|c|}{ Europe } \\
\hline & dowjones & djoneshotel & Djteleco & Djauto & djreal & & stoxx600 & eurotravel & euroreal & euroauto & europetelec \\
\hline \multirow[t]{2}{*}{ L.dowjones } & $-0.16^{* *}$ & & & & & L.stoxx600 & -0.017 & & & & \\
\hline & $(0.06)$ & & & & & & $(0.021)$ & & & & \\
\hline \multirow[t]{2}{*}{ stdrsent } & $-0.01^{* * *}$ & $-0.01^{* * *}$ & -0.00 & -0.00 & $-0.01^{* * *}$ & stdrsent & $-0.002+$ & $-0.003^{*}$ & $-0.003^{*}$ & $-0.002+$ & -0.001 \\
\hline & $(0.00)$ & $(0.00)$ & $(0.00)$ & $(0.00)$ & $(0.00)$ & & $(0.001)$ & $(0.001)$ & $(0.001)$ & $(0.001)$ & $(0.001)$ \\
\hline \multirow[t]{2}{*}{ LD.stdcases } & -0.02 & $-0.06^{* *}$ & 0.00 & $-0.05^{*}$ & $0.05^{* * *}$ & LD.stdcases & $-0.008^{* * *}$ & $-0.020^{* * *}$ & $-0.009 * * *$ & $-0.015^{* * *}$ & $-0.005^{*}$ \\
\hline & $(0.01)$ & $(0.02)$ & $(0.01)$ & $(0.03)$ & $(0.01)$ & & $(0.002)$ & $(0.005)$ & $(0.002)$ & $(0.003)$ & $(0.002)$ \\
\hline \multicolumn{2}{|l|}{ L.djonesho | } & 0.09 & & & & L.eurotravel & & $0.349 * * *$ & & & \\
\hline & & $(0.07)$ & & & & & & $(0.026)$ & & & \\
\hline \multirow[t]{2}{*}{ L.djteleco } & & & $-0.30 * * *$ & & & L.euroreal & & & $0.226 * * *$ & & \\
\hline & & & $(0.09)$ & & & & & & $(0.032)$ & & \\
\hline \multirow[t]{2}{*}{ L.djauto } & & & & $0.13+$ & & L.euroauto & & & & -0.011 & \\
\hline & & & & $(0.08)$ & & & & & & $(0.016)$ & \\
\hline \multirow[t]{2}{*}{ L.djreal } & & & & & -0.06 & L.europete ${ }^{\sim} \mathrm{C}$ & & & & & $-0.044 * * *$ \\
\hline & & & & & $(0.04)$ & & & & & & $(0.010)$ \\
\hline \multirow[t]{2}{*}{ _cons } & -0.00 & -0.00 & -0.00 & 0.00 & 0.00 & _cons & -0.002 & -0.001 & -0.000 & $-0.003^{* *}$ & $-0.002^{* *}$ \\
\hline & $(0.00)$ & $(0.00)$ & $(0.00)$ & $(0.00)$ & $(0.00)$ & & $(0.001)$ & $(0.001)$ & $(0.001)$ & $(0.001)$ & $(0.001)$ \\
\hline N & 72 & 72 & 72 & 72 & 72 & $N$ & 360 & 360 & 360 & 360 & 360 \\
\hline adj. R-sq & 0.464 & 0.574 & 0.114 & 0.114 & 0.598 & adj. R-sq & 0.0228 & 0.1621 & 0.09 & 0.022 & 0.01 \\
\hline \multicolumn{6}{|c|}{$\begin{array}{l}\text { Standard errors in parentheses } \\
+p<0.10, * p<0.05, * * p<0.01, * * * p<0.001\end{array}$} & \multicolumn{6}{|c|}{$\begin{array}{l}\text { Standard errors in parentheses } \\
+p<0.10, * p<0.05, * * p<0.01, * * * p<0.001\end{array}$} \\
\hline
\end{tabular}

Note: Table 3 reports the influence of standardized sentiment index and standardized first lagged difference of COVID-19 cases on global and sector return indexes or ETFs. For the US globally (dowjones) has more sensitivity to sentiment ( $0.1 \%$ alpha) and in tourism sector and real estate $(0.1 \%$ alpha). Real cases affect also real estate with an $\alpha=0,1 \%$. For Europe as a whole, markets are more prone to rationality as it can observe that the market as a whole and all sectors are influenced by rational events $(\alpha=0.1 \%$ with the exception of telecom sector. 


\begin{tabular}{|c|c|c|c|c|c|c|c|c|c|c|c|}
\hline \multicolumn{6}{|c|}{ Spain } & \multicolumn{6}{|c|}{ Italy } \\
\hline & -1 & -2 & -3 & -4 & -5 & & -1 & -2 & -3 & -4 & -5 \\
\hline & stoxx600 & eurotravel & euroreal & euroauto & europetelec & & stoxx600 & eurotravel & euroreal & euroauto & europetelec \\
\hline \multirow[t]{2}{*}{ L.stoxx600 } & 0.105 & & & & & L.stoxx600 & 0.037 & & & & \\
\hline & $(0.081)$ & & & & & & $(0.083)$ & & & & \\
\hline \multirow[t]{2}{*}{ stdrsent } & 0.001 & $-0.007 * *$ & -0.000 & 0.002 & $-0.003+$ & stdrsent & $-0.004^{*}$ & $-0.009^{* * *}$ & $-0.003^{*}$ & -0.002 & $-0.004^{* * *}$ \\
\hline & $(0.002)$ & $(0.002)$ & $(0.002)$ & $(0.002)$ & $(0.002)$ & & $(0.001)$ & $(0.002)$ & $(0.001)$ & $(0.002)$ & $(0.001)$ \\
\hline \multirow[t]{2}{*}{ LD.stdcases } & 0.006 & $-0.053^{* * *}$ & -0.006 & -0.003 & 0.006 & LD.stdcases & $-0.049 * * *$ & $-0.083^{* * *}$ & $-0.041 * * *$ & $-0.057 * * *$ & 0.006 \\
\hline & $(0.008)$ & $(0.009)$ & $(0.007)$ & $(0.010)$ & $(0.006)$ & & (0.009) & $(0.012)$ & $(0.008)$ & $(0.012)$ & $(0.008)$ \\
\hline \multirow[t]{2}{*}{ L.eurotravel } & & $0.141^{*}$ & & & & L.eurotravel & & $0.227^{* *}$ & & & \\
\hline & & $(0.062)$ & & & & & & $(0.079)$ & & & \\
\hline \multirow[t]{2}{*}{ L.euroreal } & & & $0.288^{* * *}$ & & & L.euroreal & & & $0.275^{* * *}$ & & \\
\hline & & & $(0.074)$ & & & & & & $(0.077)$ & & \\
\hline \multirow[t]{2}{*}{ L.euroauto } & & & & 0.061 & & L.euroauto & & & & -0.038 & \\
\hline & & & & $(0.068)$ & & & & & & $(0.072)$ & \\
\hline \multirow[t]{2}{*}{ L.europete ${ }^{\sim} \mathrm{c}$} & & & & & 0.038 & L.europete ${ }^{\sim} \mathrm{C}$ & & & & & -0.021 \\
\hline & & & & & $(0.065)$ & & & & & & (0.069) \\
\hline \multirow[t]{2}{*}{ _cons } & 0.000 & -0.001 & 0.001 & -0.003 & -0.000 & _cons & 0.002 & 0.002 & 0.002 & -0.002 & 0.000 \\
\hline & $(0.003)$ & $(0.003)$ & $(0.002)$ & $(0.003)$ & $(0.002)$ & & $(0.002)$ & $(0.003)$ & $(0.002)$ & $(0.003)$ & $(0.002)$ \\
\hline N & 72 & 72 & 72 & 72 & 72 & $N$ & 72 & 72 & 72 & 72 & 72 \\
\hline adj. R-sq & -0.007 & 0.426 & 0.168 & -0.020 & 0.022 & adj. R-sq & 0.404 & 0.657 & 0.538 & 0.242 & 0.132 \\
\hline \multicolumn{6}{|c|}{$\begin{array}{l}\text { Standard errors in parentheses } \\
+p<0.10, * p<0.05, * * p<0.01, * * * p<0.001\end{array}$} & \multicolumn{6}{|c|}{$\begin{array}{l}\text { Standard errors in parentheses } \\
+p<0.10, * p<0.05, * * p<0.01, * * * p<0.001\end{array}$} \\
\hline
\end{tabular}

Note: Table 4 reports the influence of standardized sentiment index and standardized first lagged difference of COVID-19 cases on global and sector return indexes or ETFs. Spain's tourism returns are affected by real cases, and Italy is more rationally affected globally in tourism, real estate, and auto industries. 
Table 5. OLS robust regressions for Germany and UK

\begin{tabular}{|c|c|c|c|c|c|c|c|c|c|c|c|}
\hline \multicolumn{6}{|c|}{ Germany } & \multicolumn{6}{|c|}{ UK } \\
\hline & -1 & -2 & -3 & -4 & -5 & & -1 & -2 & -3 & -4 & -5 \\
\hline & stoox600 & eurotravel & euroreal & euroauto & europetelec & & stoxx600 & eurotravel & euroreal & euroauto & europetelec \\
\hline \multirow[t]{2}{*}{ L.stoxx600 } & $0.113+$ & & & & & L.stoxx600 & 0.117 & & & & \\
\hline & $(0.061)$ & & & & & & $(0.086)$ & & & & \\
\hline \multirow[t]{2}{*}{ stdrsent } & $0.003^{* * *}$ & $-0.003^{*}$ & -0.000 & 0.002 & -0.001 & stdrsent & 0.001 & -0.002 & -0.000 & $0.002+$ & $-0.002^{* * *}$ \\
\hline & $(0.001)$ & $(0.001)$ & $(0.001)$ & $(0.001)$ & $(0.001)$ & & $(0.001)$ & $(0.001)$ & $(0.001)$ & $(0.001)$ & $(0.001)$ \\
\hline \multirow[t]{2}{*}{ LD.stdcases } & -0.003 & $-0.024 * *$ & $-0.010+$ & -0.008 & $-0.009+$ & LD.stdcases & 0.001 & 0.009 & -0.001 & 0.001 & 0.004 \\
\hline & $(0.005)$ & $(0.008)$ & $(0.005)$ & $(0.008)$ & $(0.005)$ & & $(0.007)$ & $(0.009)$ & $(0.006)$ & $(0.009)$ & $(0.005)$ \\
\hline \multirow[t]{2}{*}{ L.eurotravel } & & $0.459^{* * *}$ & & & & L.eurotravel & & $0.565 * * *$ & & & \\
\hline & & $(0.071)$ & & & & & & $(0.073)$ & & & \\
\hline \multirow[t]{2}{*}{ L.euroreal } & & & $0.301^{* * *}$ & & & L.euroreal & & & $0.292^{* * *}$ & & \\
\hline & & & $(0.070)$ & & & & & & $(0.078)$ & & \\
\hline \multirow[t]{2}{*}{ L.euroauto } & & & & 0.052 & & L.euroauto & & & & 0.100 & \\
\hline & & & & $(0.069)$ & & & & & & $(0.070)$ & \\
\hline \multicolumn{2}{|l|}{ L.europete ${ }^{\sim} \mathrm{c}$} & & & & 0.025 & \multicolumn{2}{|l|}{ L.europete ${ }^{\sim}$} & & & & 0.044 \\
\hline & & & & & $(0.061)$ & & & & & & $(0.064)$ \\
\hline \multirow[t]{2}{*}{ _cons } & 0.001 & -0.002 & 0.001 & -0.004 & -0.001 & cons & 0.000 & 0.000 & 0.001 & -0.004 & 0.000 \\
\hline & $(0.002)$ & $(0.003)$ & $(0.002)$ & $(0.003)$ & $(0.002)$ & & $(0.002)$ & $(0.003)$ & $(0.002)$ & $(0.003)$ & $(0.002)$ \\
\hline$N$ & 72 & 72 & 72 & 72 & 72 & $N$ & 72 & 72 & 72 & 72 & 72 \\
\hline adj. R-sq & 0.170 & 0.459 & 0.231 & -0.002 & 0.040 & adj. R-sq & -0.009 & 0.537 & 0.169 & 0.017 & 0.183 \\
\hline \multicolumn{6}{|c|}{$\begin{array}{l}\text { Standard errors in parentheses } \\
+p<0.10, * p<0.05, * * p<0.01,{ }^{* * *} p<0.001\end{array}$} & \multicolumn{6}{|c|}{$\begin{array}{l}\text { Standard errors in parentheses } \\
+p<0.10, * p<0.05, * * p<0.01, * * * p<0.001\end{array}$} \\
\hline
\end{tabular}

Note: Table 5 reports the influence of standardized sentiment index and standardized first lagged difference of COVID-19 cases on global and sector return indexes or ETFs. Germany's tourism returns are more sensitive to rationality (alpha of $1 \%$ ), and the UK's telecom sector is more sensitive to rationality. 
Table 6. OLS robust regressions for France

\begin{tabular}{|c|c|c|c|c|c|}
\hline \multicolumn{6}{|c|}{ France } \\
\hline & -1 & -2 & -3 & -4 & -5 \\
\hline & stoxx600 & eurotravel & euroreal & euroauto & europetelec \\
\hline \multirow[t]{2}{*}{ L.stoxx600 } & 0.081 & & & & \\
\hline & $(0.082)$ & & & & \\
\hline \multirow[t]{2}{*}{ stdrsent } & -0.000 & -0.001 & 0.001 & -0.001 & 0.000 \\
\hline & $(0.001)$ & $(0.002)$ & $(0.001)$ & $(0.002)$ & $(0.001)$ \\
\hline \multirow[t]{2}{*}{ LD.stdcases } & -0.003 & $-0.013^{*}$ & -0.005 & -0.003 & -0.000 \\
\hline & $(0.004)$ & $(0.006)$ & $(0.004)$ & $(0.005)$ & $(0.003)$ \\
\hline \multirow[t]{2}{*}{ L.eurotravel } & & $0.508^{* * *}$ & & & \\
\hline & & $(0.077)$ & & & \\
\hline \multirow[t]{2}{*}{ L.euroreal } & & & $0.314^{* * *}$ & & \\
\hline & & & $(0.072)$ & & \\
\hline \multirow[t]{2}{*}{ L.euroauto } & & & & 0.046 & \\
\hline & & & & $(0.070)$ & \\
\hline \multirow[t]{2}{*}{ L.europete ${ }^{c}$} & & & & & 0.016 \\
\hline & & & & & $(0.065)$ \\
\hline \multirow[t]{2}{*}{ cons } & 0.001 & -0.000 & 0.000 & -0.002 & -0.001 \\
\hline & $(0.002)$ & $(0.003)$ & $(0.002)$ & $(0.003)$ & $(0.002)$ \\
\hline$N$ & 72 & 72 & 72 & 72 & 72 \\
\hline adj. R-sq & -0.022 & 0.386 & 0.200 & -0.030 & -0.043 \\
\hline \multicolumn{6}{|c|}{$\begin{array}{l}\text { Standard errors in parentheses } \\
+p<0.10,{ }^{*} p<0.05,{ }^{* *} p<0.01, * * * p<0.001\end{array}$} \\
\hline
\end{tabular}

Note: Table 6 reports the influence of standardized sentiment index and standardized first lagged difference of COVID-19 cases on global and sector return indexes or ETFs. France tourism returns are more influenced by rationality at alpha of $5 \%$.
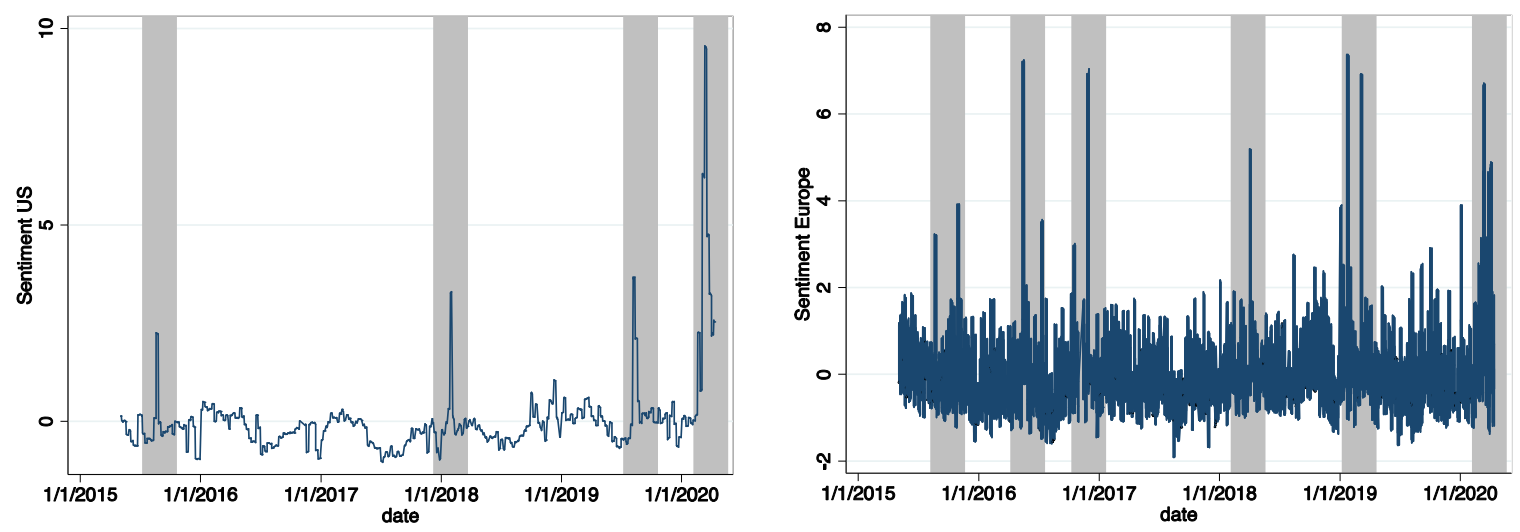

Note: Sentiment data duly standardized with mean 0 and 1 variance and on grey color the main economic and financial events that sentiment index showed during the period. The sentiment is a manifestation of the markets' irrationality and is validated because it follows the most significant happenings in the market. Per grey area: 1-China devaluates the yuan in august 2015 (MarketWatch); 2-Japanese 10y bond yield hits 0\% in January 2016 (WSJ); 3-Brexit voted in July 2016 (WSJ), and Italy's constitutional referendum and the bad loans plaguing the country's banks in November 2016 (WSJ); 4-China-US trade war (February and March 2018, fxempire.com); 5-China trade war (November 2019) and Brexit again-Britain spoke for the 2nd time and once more voted in favor of departing from the EU (Feb 2019, fxempire.com). 6-In 2020, the COVID-19 impact on the bourses.

Figure 1. Sentiment for Europe and for the US 


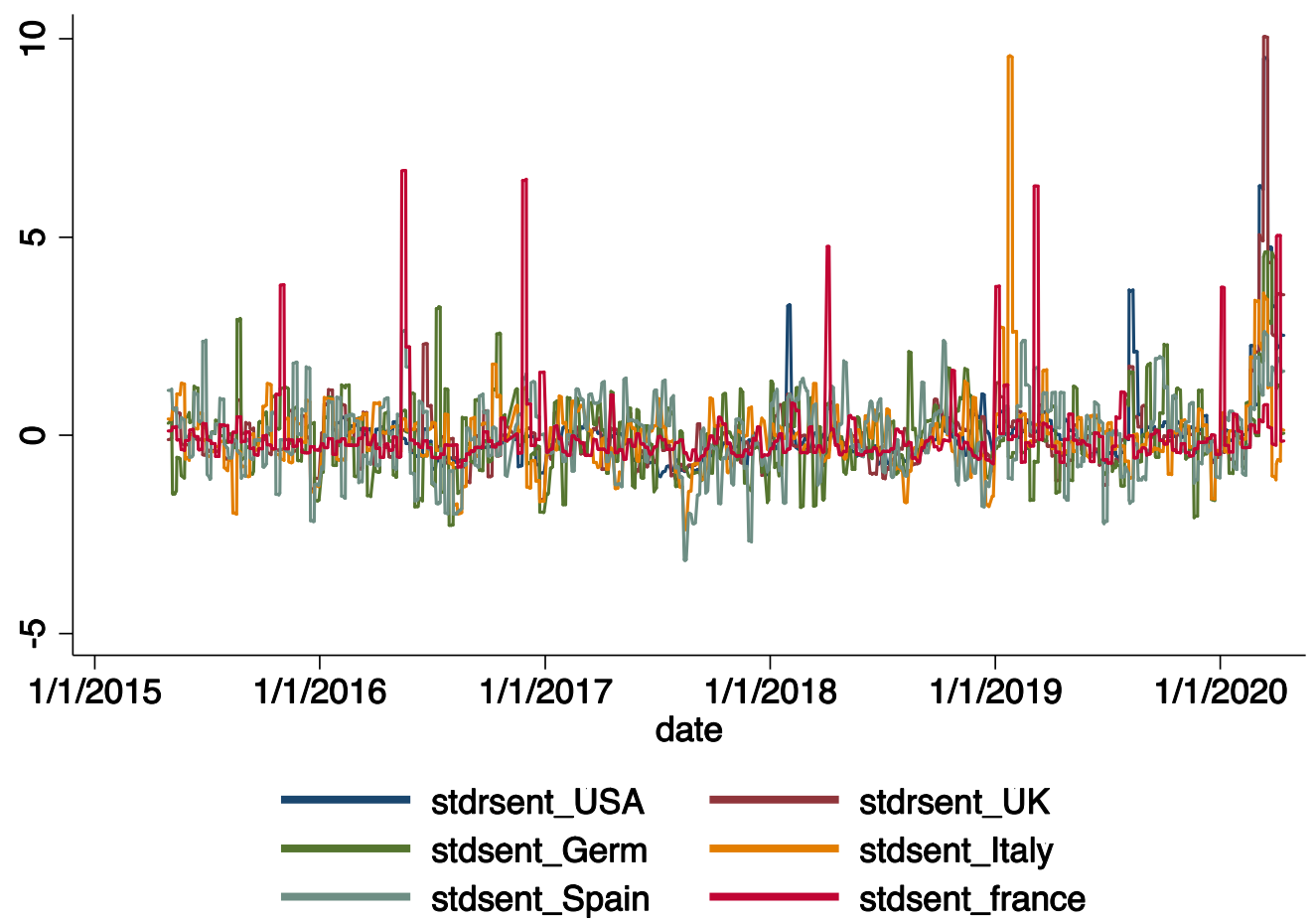

Sentiment data duly standardized with a mean 0 and 1 variance for comparison purposes

Figure 2. Sentiment for the US and European countries

Table 7. Correlation coefficients among irrational behavior measured by the sentiment index duly standardized

As of $1 / 1 / 2015$

\begin{tabular}{|c|c|c|c|c|c|c|}
\hline Section 1 & stdrsent_USA & stdrsent_UK & $\begin{array}{l}\text { stdrsent__ } \\
\text { Germany }\end{array}$ & stdrsent_Italy & stdrsent_Spain & stdrsent_France \\
\hline Stdrsent_USA & 1.0000 & & & & & \\
\hline Stdrsent_UK & 0.8580 & 1.0000 & & & & \\
\hline Stdrsent_Germany & 0.4714 & 0.4522 & 1.0000 & & & \\
\hline Stdrsent_Italy & 0.2860 & 0.3289 & 0.1447 & 1.0000 & & \\
\hline Stdrsent_Spain & 0.2694 & 0.3034 & 0.2307 & 0.2202 & 1.0000 & \\
\hline Stdrsent_France & 0.1166 & 0.1543 & 0.1092 & 0.0725 & 0.2631 & 1.0000 \\
\hline
\end{tabular}

Period of COVID-19 after 12/01/2019

\begin{tabular}{|c|c|c|c|c|c|c|}
\hline Section 2 & stdrsent_USA & stdrsent_UK & $\begin{array}{l}\text { stdrsent__ } \\
\text { Germany }\end{array}$ & stdrsent_Italy & stdrsent_Spain & stdrsent_France \\
\hline Stdrsent_USA & 1.0000 & & & & & \\
\hline Stdrsent_UK & 0.9698 & 1.0000 & & & & \\
\hline Stdrsent_Germany & 0.8366 & 0.8078 & 1.0000 & & & \\
\hline Stdrsent_Italy & 0.6139 & 0.6345 & 0.3743 & 1.0000 & & \\
\hline Stdrsent_Spain & 0.7233 & 0.8046 & 0.6894 & 0.4925 & 1.0000 & \\
\hline Stdrsent_France & 0.1302 & 0.2196 & 0.1453 & -0.0248 & 0.3032 & 1.0000 \\
\hline
\end{tabular}




\section{DISCUSSION}

An increase in negative sentiment implying fear, pessimism, and panic, is negatively associated with returns in the US global index and in tourism and in real estate, the most impacted sectors with the pandemic (Table 3). Irrationality prevails and conditions market returns. Europe also presents the same reaction, although at a lower level than in the US. In Europe, the automobile industry also was affected by investor sentiment. An increase in COVID-19 cases, although relevant in the US for the global, tourism, and real estate indexes, has a more pronounced effect on Europe in all sectors (telecommunications return has a lower reaction). Accordingly, rationality reaction prevails. The US reacts more in anticipation of the sentiment, a measure that captures actual and future concern and fear, rather than with the effective COVID cases. On the other hand, Europe seems to react more to the real scenario and landscape and lower to sentiment, to the anticipation of any scenario. The adjusted $R^{2}$ confirms the predictive power of sentiment and COVID-19 cases of returns, mainly on the more damaged sectors of the economy: hotel, leisure, and real estate. Spain and Italy are the European countries that suffered the most, and it is confirmed that the tourism sector had the most impacted returns (Table 4). Sentiment and cases both have equally predicted power on returns for Tourism. In Italy, real estate and automobile indexes returns (car makers are important in Italy) react more to the real cases than on sentiment or mood. Germany and France index returns are more prone to confirmed cases in the Tourism sector than on sentiment (Tables 5 and 6).

According to Figure 1, the sentiment index is accurate and a manifestation of irrationality, considering that it also follows the main events (whether in the US or Europe) that have affected the stock markets. For instance, the main events, such as the ones described in the note to Figure 1, justify the model's accuracy in Europe and the USA.

The contagion and spillover effect among European countries and the US are confirmed in this work. Moreover, the UK and the USA have a stronger connection to the irrational behavior of investors. This spillover effect is capitalized on the COVID-19 period, where it can be seen the panic and fear of investors more underlined (see Table 7).

Figure 2 allows concluding that among countries, the UK and the US are more prone to irrational sentiment as it can also be testified by UK sector returns that respond more to irrationality than on real COVID-19 cases (telecommunications sector). Also, Italy and France have strong irrational behavior peaks, but when confronting sector returns over the two - rational and irrationality, rationality appears as the main driver of returns on some sectors. The sentiment index captures the nervous investors before market constraints, and it seems that mood alterations are often seen in European markets than in the US. Despite the mood features, rationality is more present in European sectors than on US sector returns (see Table 3-6).

\section{CONCLUSION}

Coronavirus has brought panic, negativity, and contagious effects among global economies. Although this may have caused huge daily and accumulated losses on stock indexes also created opportunities for recoveries and huge gains. The sentiment index proved to be more effective in predicting returns than the real COVID-19 cases that conditioned the market. This encompasses the idea that irrational feelings than rational ones mainly condition investor behavior. The research question is duly answered considering that the US reacted in anticipation when compared with Europe as a whole or even before country-specific effects, and so subject to more irrationality behavior despite the possibility of being more future assertive. Tourism (travel and leisure) and real estate sectors are the more responsive ones to investors' irrational behavior in the US, while tourism, real estate, and automobile are more affected by rationality in Europe. This may prove that even before market contagion and spillovers, the US stock markets react more to the anticipation of bad news and worst scenarios than Europe that reacts more to real pandemic verified confirmed cases. The excessive financial news providers with corporations such as the CNBC, Thomson Reuters, Bloomberg, Wall Street Journal, Moody's, S\&P GMI, MSCI, 
Morningstar, Refinitiv, MarketWatch, etc., the huge number of analysts and commentators that appear on news channels, whether online or on TV, create a strong dynamic of the information market in the US. This information market is more advanced than in Europe, boosting the investors' concern and search for the quicker source of new news. This information absorption leads investors to make their investments based on assumptions of the market's future behavior than on real COVID-19 cases.

Emotions drive asset prices, and even though Europe appears to react more to rational factors than the US does not mean that European investors can earn more money than American ones.

This study's limitation is that it was not analyzed with Asian data (namely China), where the outbreak started because the sentiment index was not possible to build due to the words' translation problems.

\section{ACKNOWLEDGMENT}

This work is funded by National Funds through the FCT - Foundation for Science and Technology, I.P., within the scope of the project $\operatorname{Ref}^{\mathrm{a}} \mathrm{UIDB} / 05583 / 2020$. Furthermore, we would like to thank the Research Centre in Digital Services (CISeD) and the Polytechnic Institute of Viseu for their support.

\section{AUTHOR CONTRIBUTIONS}

Conceptualization: Pedro Manuel Nogueira Reis, Carlos Pinho.

Data curation: Pedro Manuel Nogueira Reis, Carlos Pinho.

Formal analysis: Pedro Manuel Nogueira Reis, Carlos Pinho.

Funding acquisition: Pedro Manuel Nogueira Reis, Carlos Pinho.

Investigation: Pedro Manuel Nogueira Reis, Carlos Pinho.

Methodology: Pedro Manuel Nogueira Reis, Carlos Pinho.

Project administration: Pedro Manuel Nogueira Reis, Carlos Pinho.

Resources: Pedro Manuel Nogueira Reis, Carlos Pinho.

Software: Pedro Manuel Nogueira Reis, Carlos Pinho.

Supervision: Pedro Manuel Nogueira Reis, Carlos Pinho.

Validation: Pedro Manuel Nogueira Reis, Carlos Pinho.

Visualization: Pedro Manuel Nogueira Reis, Carlos Pinho.

Writing - original draft: Pedro Manuel Nogueira Reis, Carlos Pinho.

Writing - review \& editing: Pedro Manuel Nogueira Reis, Carlos Pinho.

\section{REFERENCES}

1. Aggarwal, D. (2019). Defining and measuring market sentiments: a review of the literature. Qualitative Research in Financial Markets, ahead-of-print. https://doi. org/10.1108/QRFM-03-2018-0033

2. Al-Awadhi, A. M., Al-Saifi, K., Al-Awadhi, A., \& Alhamadi, S. (2020). Death and contagious infectious diseases: Impact of the COVID-19 virus on stock market returns. Journal of Behavioral and Experimental Finance, 27, 100326. https://doi.org/10.1016/j. jbef.2020.100326
3. Ali, M., Alam, N., \& Rizvi, S. A. R. (2020). Coronavirus (COVID-19) - An epidemic or pandemic for financial markets. Journal of Behavioral and Experimental Finance, 27, 100341. https://doi.org/10.1016/j. jbef.2020.100341

4. Baker, M., \& Wurgler, J. (2006). Investor sentiment and the crosssection of stock returns. Journal of Finance, 61(4), 1645-1680. https://doi.org/10.1111/j.15406261.2006.00885.x

5. Baker, S. R., Bloom, N., Davis, S. J., Kost, K. J., Sammon, M. C., \&
Viratyosin, T. (2020). The unprecedented stock market impact of COVID-19 (No. w26945). National Bureau of Economic Research. Retrieved from https://www.nber. org/papers/w26945

6. Benhabib, J., Liu, X., \& Wang, P. (2016). Sentiments, financial markets, and macroeconomic fluctuations. Journal of Financial Economics, 120(2), 420-443. http://dx.doi. org/10.1016/j.jfineco.2016.01.008

7. Cheema, M. A., Man, Y., \& Szulczyk, K. R. (2020). Does investor sentiment predict the near-term 
returns of the Chinese stock market? International Review of Finance, 20(1), 225-233. https://doi. org/10.1111/irfi.12202

8. Chen, C., Liu, L., \& Zhao, N. (2020). Fear Sentiment, Uncertainty, and Bitcoin Price Dynamics: The Case of COVID-19. Emerging Markets Finance and Trade, 56(10), 2298-2309. https://doi.org/10.1080/ 1540496X.2020.1787150

9. Corbet, S., Larkin, C., \& Lucey, B. (2020). The contagion effects of the COVID-19 pandemic: Evidence from Gold and Cryptocurrencies. Finance Research Letters, 101554. https://doi.org/10.1016/j. frl.2020.101554

10. Da, Z., Engelberg, J., \& Gao, P. (2015). The sum of all FEARS investor sentiment and asset prices. The Review of Financial Studies, 28(1), 1-32. https://doi.org/10.1093/ rfs/hhu072

11. Ding, W., Mazouz, K., \& Wang, Q. (2018). Investor sentiment and the cross-section of stock returns: New theory and evidence. Review of Quantitative Finance and Accounting, 53(2), 493-525. https://doi. org/10.1007/s11156-018-0756-Z

12. European Centre for Disease Prevention and Control. (2020). COVID-19 Coronavirus data. Retrieved from https://data.europa eu/euodp/pt/data/dataset/covid19-coronavirus-data

13. Fisher, K. L., \& Statman, M (2000). Investor sentiment and stock returns. Financial Analysts Journal, 56(2), 16-23. https://doi. org/10.2469/faj.v56.n2.2340

14. Gao, Z., Ren, H., \& Zhang, B. (2018). Googling investor sentiment around the world. Journal of Financial and Quantitative Analysis (JFQA), forthcoming. Retrieved from https://papers.ssrn.com/sol3/ papers.cfm?abstract_id=2725072

15. Giglio, S., \& Kelly, B. (2017). Excess volatility: Beyond discount rates. The Quarterly Journal of Econom ics, 133(1), 71-127. http://dx.doi. org/10.1093/qje/qjx034

16. Gunay, S. (2020). A New Form of Financial Contagion: COVID-19 and Stock Market Responses. http://dx.doi.org/10.2139/ ssrn. 3584243
17. Haroon, O., \& Rizvi, S. A. R. (2020). COVID-19: Media coverage and financial markets behavior-A sectoral inquiry. Journal of Behavioral and Experimental Finance, 27, 100343. https://doi.org/10.1016/j. jbef.2020.100343

18. Huber, P. J. (1973). Robust Regression: Asymptotics, Conjectures and Monte Carlo. The Annals of Statistics, 1(5), 799-821. Retrieved from https://projecteuclid.org/ euclid.aos/1176342503

19. Jitmaneeroj, B. (2017). Does investor sentiment affect price-earnings ratios? Studies in Economics and Finance, 34(2), 183-193. http://dx.doi. org/10.1108/sef-09-2015-0229

20. Lee, W. Y., Jiang, C. X., \& Indro, D. C. (2002). Stock market volatility, excess returns, and the role of investor sentiment. Journal of Banking \& Finance, 26(12), 22772299. https://doi.org/10.1016/ s0378-4266(01)00202-3

21. Liu, H., Manzoor, A., Wang, C., Zhang, L., \& Manzoor, Z. (2020). The COVID-19 outbreak and affected countries stock markets response. International Journal of Environmental Research and Public Health, 17(8), 2800. https://doi. org/10.3390/ijerph17082800

22. Onali, E. (2020). COVID-19 and Stock Market Volatility (May 28, 2020). Retrieved from http://dx.doi. org/10.2139/ssrn.3571453

23. Papadamou, S., Fassas, A., Kenourgios, D., \& Dimitriou, D. (2020). Direct and Indirect Effects of COVID-19 Pandemic on Implied Stock Market Volatility: Evidence from Panel Data Analysis (MPRA Paper No. 100020, posted 04 May 2020 11:30 UTC). Retrieved from https://mpra.ub.uni-muenchen. de/100020/

24. Reis, P. M. N., \& Pinho, C. (2020a). A Reappraisal of the Causal Relationship between Sentiment Proxies and Stock Returns. Journal of Behavioral Finance, 1-23. https:// doi.org/10.1080/15427560.2020.1 792910

25. Reis, P. M. N., \& Pinho, C. (2020b). A new European investor sentiment index (EURsent) and its return and volatility predictability. Journal of Behavioral and Experi- mental Finance, 27, 100373. https:// doi.org/10.1016/j.jbef.2020.100373

26. Salisu, A. A., \& Akanni, L. O. (2020). Constructing a global fear index for the COVID-19 pandemic. Emerging Markets Finance and Trade, 56(10), 2310-2331. https://doi.org/10.1080/154049 6X.2020.1785424

27. Schatteman, A. M., \& Waymire, T. R. (2017). The state of nonprofit finance research across disciplines. Nonprofit Management and Leadership, 28(1), 125-137. https://doi. org/10.1002/nml.21269

28. Sharma, A., \& Kumar, A. (2019). A review paper on behavioral finance: study of emerging trends. Qualitative Research in Financial Markets, 12(2), 137-157. https://doi. org/10.1108/QRFM-06-2017-0050

29. Tuckett, D., \& Taffer, R. (2008). Phantastic objects and the financial market's sense of reality: a psychoanalytic contribution to the understanding of stock market instability. The International Journal of Psychoanalysis, 89(2), 389-412. https://doi.org/10.1111/j.17458315.2008.00040.x

30. Verma, R., Baklaci, H., \& Soydemir, G. (2008). The impact of rational and irrational sentiments of individual and institutional investors on DJIA and S\&P500 index returns. Applied Financial Economics, 18(16), 1303-1317. https://doi. org/10.1080/09603100701704272

31. Zhang, D., Hu, M., \& Ji, Q. (2020) Financial markets under the global pandemic of COVID-19. Finance Research Letters, 36, 101528. https://doi.org/10.1016/j. frl.2020.101528

32. Zhang, Z. (1997). Parameter estimation techniques: A tutorial with application to conic fitting. Image and Vision Computing, 15(1), 59-76. Retrieved from https://hal.inria.fr/ inria-00074015/document

33. Zhou, G. (2018). Measuring investor sentiment. Annual Review of Financial Economics, 10, 239-259. http://dx.doi.org/10.1146/annurevfinancial-110217-022725 